\title{
The extreme melt across the Greenland ice sheet in 2012
}

\author{
S. V. Nghiem, ${ }^{1}$ D. K. Hall, ${ }^{2}$ T. L. Mote, ${ }^{3}$ M. Tedesco, ${ }^{4}$ M. R. Albert, ${ }^{5}$ K. Keegan, ${ }^{5}$ \\ C. A. Shuman, ${ }^{6}$ N. E. DiGirolamo, ${ }^{7}$ and G. Neumann ${ }^{1}$ \\ Received 24 August 2012; revised 25 September 2012; accepted 26 September 2012; published 27 October 2012.
}

[1] The discovery of the 2012 extreme melt event across almost the entire surface of the Greenland ice sheet is presented. Data from three different satellite sensors - including the Oceansat-2 scatterometer, the Moderate-resolution Imaging Spectroradiometer, and the Special Sensor Microwave Imager/ Sounder - are combined to obtain composite melt maps, representing the most complete melt conditions detectable across the ice sheet. Satellite observations reveal that melt occurred at or near the surface of the Greenland ice sheet across $98.6 \%$ of its entire extent on 12 July 2012 , including the usually cold polar areas at high altitudes like Summit in the dry snow facies of the ice sheet. This melt event coincided with an anomalous ridge of warm air that became stagnant over Greenland. As seen in melt occurrences from multiple ice core records at Summit reported in the published literature, such a melt event is rare with the last significant one occurring in 1889 and the next previous one around seven centuries earlier in the Medieval Warm Period. Given its rarity, the 2012 extreme melt across Greenland provides an exceptional opportunity for new studies in broad interdisciplinary geophysical research. Citation: Nghiem, S. V., D. K. Hall, T. L. Mote, M. Tedesco, M. R. Albert, K. Keegan, C. A. Shuman, N. E. DiGirolamo, and G. Neumann (2012), The extreme melt across the Greenland ice sheet in 2012, Geophys. Res. Lett., 39, L20502, doi:10.1029/2012GL053611.

\section{Introduction}

[2] The Greenland ice sheet (GIS) holds a massive amount of water equivalent to 6-7 m of contemporary sea level rise (SLR) if it were to melt completely [Cuffey and Marshall, 2000]. The Copenhagen Diagnosis reported that previous Intergovernmental Panel on Climate Change (IPCC) predictions underestimated global SLR by as much as $80 \%$ [Allison et al., 2009]. Future SLR projections are challenging in a non-stationary climate change, where a past climate

\footnotetext{
${ }^{1}$ Jet Propulsion Laboratory, California Institute of Technology, Pasadena California, USA

${ }^{2}$ NASA Goddard Space Flight Center, Greenbelt, Maryland, USA.

${ }^{3}$ Department of Geography, University of Georgia, Athens, Georgia, USA.

${ }^{4}$ Department of Earth and Atmospheric Sciences, City University of New York, New York, New York, USA.

${ }^{5}$ Thayer School of Engineering, Dartmouth College, Hanover, New Hampshire, USA.

${ }^{6}$ Joint Center for Earth Systems Technology, University of Maryland, Baltimore County, Baltimore, Maryland, USA.

${ }^{7}$ Science System and Application, Inc., Lanham, Maryland, USA.

Corresponding author: S. V. Nghiem, Jet Propulsion Laboratory, California Institute of Technology, MS 300-235, 4800 Oak Grove Dr., Pasadena, CA 91109, USA. (son.v.nghiem@jpl.nasa.gov)

C2012. American Geophysical Union. All Rights Reserved. 0094-8276/12/2012GL053611
}

trend cannot be used to predict the future. The estimation of change in total GIS mass balance is intricately related to competing changes in mass outflux and influx: While melt and runoff have increased in the past several decades, snow accumulation has also increased [Hanna et al., 2008]. Adding to the complexity are anomalous events, detected in decadal datasets from satellites, in snow accumulation [Nghiem et al., 2005] and snowmelt [Abdalati and Steffen, 1997; Nghiem et al., 2001; Steffen et al., 2004; Mote, 2007; Tedesco et al., 2008; Hall et al., 2009]. Thus, observations of extreme events become more crucial to closely monitor substantial changes that may potentially impact the GIS mass balance and consequently SLR. Here we report an extreme event of melt that extended across almost the entire GIS surface in July 2012 as observed by three different satellites, in-situ measurements, and field observations.

\section{Satellite Observations}

[3] The July 2012 extreme melt event was discovered from satellite data acquired by the scatterometer on the Indian Oceansat-2 satellite (OS2). This melt event was then confirmed by data from the Moderate-resolution Imaging Spectroradiometer (MODIS) on NASA's Terra and Aqua satellites and from the Special Sensor Microwave Imager/ Sounder (SSMIS) on a Defense Meteorological Satellite Program (DMSP) satellite. In the following paragraphs, we explain how the different satellite sensors detect melt at or near the surface of the GIS, and how the results are combined to obtain the most complete observations across the ice sheet.

[4] A scatterometer is an accurate and stable radar. In June 1999, NASA launched the SeaWinds scatterometer aboard the QuikSCAT satellite (QS), which collected radar data at the Ku-band frequency of $13.4 \mathrm{GHz}$ with a nearly daily global coverage until November 2009. The OS2 scatterometer, similar to QS, launched by the Indian Space Research Organisation (ISRO) in September 2009 continues the Ku-band scatterometer global data collection to the present. A scatterometer transmits electromagnetic waves and measures the returned power of the waves scattered back from the snow and ice on the ice sheet, which is quantified by a radar parameter called backscatter [Tsang et al., 1985].

[5] Ku-band scatterometer backscatter is highly sensitive to snow wetness, allowing Ku-band backscatter to be used for snowmelt detection [Nghiem et al., 2001]. This is because $\mathrm{Ku}$-band backscatter is strongly dependent on the imaginary part of the permittivity of liquid water, which is 19,000 times larger than that of non-melting ice [Klein and Swift, 1977; Tiuri et al., 1984]. The permittivity of a medium is a complex number, consisting of a real part and an imaginary part, defined to characterize electromagnetic wave propagation and attenuation in such medium [Tsang et al., 1985]. Since dry snow has a much smaller imaginary part of the effective 
permittivity compared to that of wet snow, Ku-band waves can penetrate more than $1 \mathrm{~m}$ [Nghiem et al., 2005] below the surface layer of refrozen snow to detect subsurface wet snow due to an internal snow temperature profile that has not yet reached the freezing point.

[6] For scatterometer data, we use the diurnal difference approach to detect and map melt on the GIS [Nghiem et al., 2001]. This approach identifies differential liquid water contained in the snow at two different times of the day between day and night passes of the satellite. Thus, melt is detected by the existence of liquid water itself rather than by temperature measurements. This means that satellite scatterometer data do not have to be collected exactly at the time when the physical temperature at the snow surface reaches the melting point. This is because of the "melt memory" from the retention of liquid water remaining in subsurface snow for some time before it totally refreezes again after air temperatures drop and the snow surface starts to refreeze. Furthermore, the diurnal approach can sense the meltwater in the snow during the time intervening between day and night passes of the satellite.

[7] The scatterometer diurnal approach for melt detection was first developed for use with QS data [Nghiem et al., 2001], and has been adapted for use with the new OS2 data acquired along orbit passes at equatorial local overpass times around noon and midnight [SCAT-DP Team, 2010]. OS2 science data are available with a latency of one to two days including the time for data processing and data transfer to local servers. Melt is detected and mapped in a simple geographic projection with a posting grid of $0.25^{\circ}$ in latitude and $0.25^{\circ}$ in longitude. Note that this is the pixel size in the data posting grid, and the resolution of OS2 data is determined by the footprint size of $27 \times 45 \mathrm{~km}$ for the inner beam and $30 \times$ $68 \mathrm{~km}$ for the outer beam [SCAT-DP Team, 2010], or roughly $40 \mathrm{~km}$ in linear dimension on average.

[8] A passive microwave radiometer measures microwave radiation emitted from snow and ice on the ice sheet and the surrounding environment. A radiometer measurement is quantified by a parameter called brightness temperature, which is essentially a product of physical temperature and emissivity [Tsang et al., 1985] that determines the amount of radiation from the ice sheet. The emissivity is a function of snow effective permittivity and thus is also sensitive to liquid water in snow or on ice. Although brightness temperature carries information about physical temperature that can be below or reach $0^{\circ} \mathrm{C}$ as the ice freezes or melts, it is the change in emissivity when liquid water is present that enables the use of passive microwave data for melt detection and mapping. Similar to scatterometer data, a radiometer identifies melt by the presence of liquid water and can detect both surface and subsurface melt $(>1 \mathrm{~m})$.

[9] Data from multiple satellite passive radiometers have been acquired almost continuously for more than three decades. The first SSM/I sensor was launched aboard the DMSP F-8 mission in 1987 [Hollinger et al., 1987]. A series of SSM/I sensors on subsequent DMSP satellites has provided a continuous data stream since then. The SSM/I sensor was replaced by the SSMIS sensor with the launch of F-16 in 2003. SSMIS has a footprint of $47 \times 73 \mathrm{~km}$ at $19 \mathrm{GHz}$ and $31 \times 41 \mathrm{~km}$ at $37 \mathrm{GHz}$ with the equatorial local overpass times around 6 am and 6 pm. Near-real-time SSMIS Daily Polar Gridded Brightness Temperatures and brightness temperatures in the Equal Area Earth Scalable (EASE) grid at
$25 \mathrm{~km}$ are available through the National Snow and Ice Data Center in Boulder, Colorado.

[10] Changes in melt duration and extent on the Greenland ice sheet have been mapped with passive microwave data, using the seasonal change in emissivity [Mote and Anderson, 1995; Mote, 2007], the frequency dependence of emissivity in the cross polarized gradient ratio [Abdalati and Steffen, 1997; Steffen et al., 2004], and the diurnal change in emissivity [Tedesco, 2007]. The melt algorithms here follow Mote and Anderson [1995] and Tedesco [2007]. Two different products derived from the same satellite and two independently developed retrieval algorithms were used for the melt detection. The difference between the two brightness temperature datasets results from (1) the projection used, (2) the use of daily averaged versus ascending and descending overpasses, and (3) the land-ice-ocean mask applied.

[11] The use of two passive microwave algorithms and products is helpful for generating more confidence on the observed extreme melting and also allows an error analysis. One algorithm is based on the diurnal difference between nighttime and daytime measurements and on a threshold value on brightness temperatures at $\sim 19 \mathrm{GHz}$ to detect melting [Tedesco, 2007] and uses EASE Grid brightness temperatures. The other algorithm is a dynamic threshold algorithm (DTA) based on a simple microwave-emission model [Mote and Anderson, 1995], which is used to simulate $37 \mathrm{GHz}$, horizontally polarized, brightness temperatures associated with $1 \%$ liquid water content locations across the Greenland ice sheet [Mote, 2007], and uses daily averaged polar gridded brightness temperatures.

[12] A spectroradiometer is a radiometer measuring the spectral power distribution of illuminants in the visible through infrared (IR) range of the electromagnetic spectrum. From spectroradiometer data and an algorithm including cloud masking, ice surface temperatures (IST) are derived to identify melt on the surface of the GIS. To detect melt, we use an IST threshold of $-1^{\circ} \mathrm{C}$. If the IST of a pixel is equal to or greater than $-1{ }^{\circ} \mathrm{C}$, we consider that pixel as "melt." Using IR data, melt is detected at the very surface $(<2 \mu \mathrm{m}$ penetration into the surface snow) of the interface between air and snow/ice. An IR sensor can measure the surface temperature accurately only under clear sky conditions.

[13] The MODIS instrument employs a cross-track scan mirror, collecting optics, and a set of individual detector elements to provide imagery of the Earth's surface and clouds in 36 discrete, narrow spectral bands from approximately 0.4 to $14.0 \mu \mathrm{m}$. MODIS was first launched in December 1999 on the Terra satellite; a second MODIS, nearly identical to the first one, was launched in May 2002. Both instruments are still operating in low-Earth orbits.

[14] The swath width of the MODIS instruments is $2330 \mathrm{~km}$. The spatial resolution of the MODIS instrument varies with spectral band, and ranges from $250 \mathrm{~m}$ to $1 \mathrm{~km}$ at nadir. Two IR bands are used: bands $31(10.780-11.280 \mu \mathrm{m})$ and $32(11.770-12.270 \mu \mathrm{m})$ are used to derive the MODIS IST product, along with a cloud mask developed by Ackerman et al. [1998, 2008]. The maximum spatial resolution of the MODIS IR bands 31 and 32 is $1 \mathrm{~km}$. The Terra overpass times are around 10:30 am and 10:30 pm, and those of Aqua are around 1:30 am and 1:30 pm equatorial local time.

[15] The IST product was developed from the heritage code of Key and Haefliger [1992] using Advanced Very High Resolution Radiometer (AVHRR) data, which was adapted 


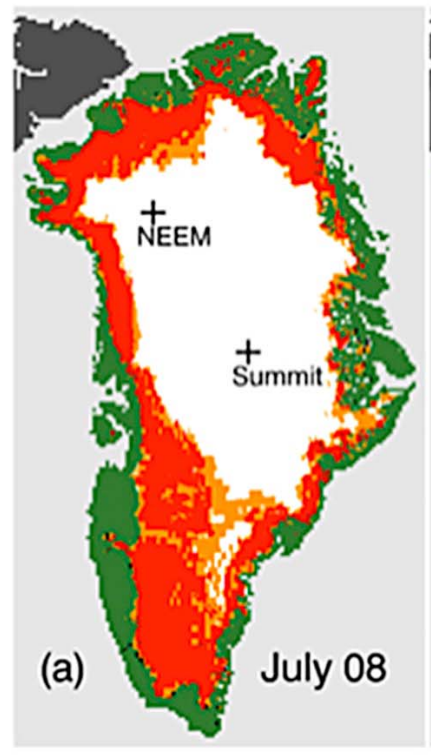

No melt

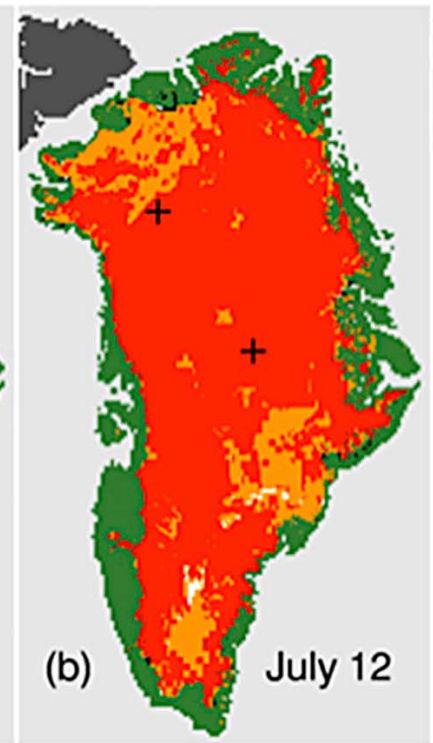

Melt seen by one sensor
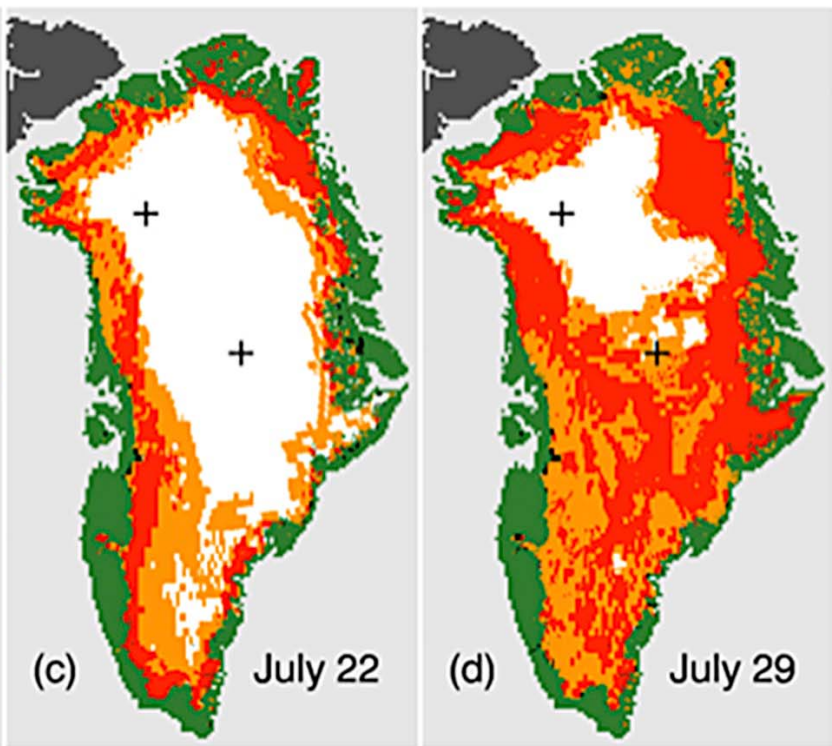

Melt seen by two or more sensors

Figure 1. Composite maps of melt extent from OS2, SSMIS, and MODIS satellite data for: (a) 8 July, (b) 12 July, (c) 22 July, and (d) 29 July 2012. In the red areas, two or more of the satellites detected melt while in the orange areas only one satellite detected melt. No melt was detected in the white areas, black indicates insufficient data, green and dark grey show land, and light grey represents ocean.

to work with MODIS. A description of the IST algorithm can be found in Hall et al. [2004]. The accuracy of the IST algorithm has been assessed by several authors [Hall et al., 2004, 2008, 2012; Scambos et al., 2006]. With the IST cutoff of $-1{ }^{\circ} \mathrm{C}$, MODIS melt maps described herein are produced in a grid with a pixel size of $6.25 \mathrm{~km}$.

[16] Here, we combine melt detected independently by all of the three sensors on OS2, SSMIS, and MODIS to obtain composite melt maps over the GIS. These composite melt maps represent the most complete melt conditions detectable across the ice sheet. This is because each satellite has a different sensitivity to melt, different resolution, different spatial coverage in different regions, different data acquisition at different times of the day, and a different capability to detect surface or subsurface melt with or without the "melt memory."

[17] While MODIS requires clear-sky conditions, OS2 and SSMIS can see through clouds, with fewer atmospheric effects at lower frequencies, providing complementary observations that fill in observation gaps in the different satellite observations for melt mapping. While OS2 and SSMIS have low resolutions, MODIS has the highest resolution of the three satellite instruments, thus providing finer spatial detail of melt patterns when not obscured by clouds. To obtain composite melt maps, melt detection data from all three satellites are coregistered and re-gridded into a common grid with a pixel size of $6.25 \mathrm{~km}$, which is not the pixel resolution of any of the instruments.

[18] Figure 1 presents melt-mapping results on several key days in July 2012 before, during and after the extreme melt event. A majority of the melt was detected by at least two satellites (red areas in Figure 1) while some other areas were detected by only one satellite (orange areas) that filled the observation gaps to provide a more complete met detection.
By 8 July 2012, melt occurred in the southern part of the GIS and in the percolation facies in the outer band around the ice sheet (Figure 1a), with a total melt extent covering $43.7 \%$ of the GIS surface. This melt pattern is about normal for that time of the year according to the average from passive microwave satellite observations.

[19] Four days later by 12 July 2012, the extreme melt event occurred as the satellite sensors identified melt at or near the surface across $98.6 \%$ of the ice sheet (Figure 1b). The extreme melt even covered the entire dry snow facies [Benson, 1962] in central Greenland where melt rarely occurs. In fact, the detection of this extreme melting is unprecedented in the satellite data record extending over more than the past three decades [Mote, 2007]. To put this extreme melt event in perspective, note that the dry snow facies is found at high latitudes and high altitudes with the highest area well above 3000 masl. At Summit Station ( 3216 masl) in the central dry snow facies, in-situ measurements and observations will be shown later as a supporting evidence of this melt event.

[20] The refreezing process reduced the melt extent back to normal conditions as shown in the composite melt map of 22 July 2012 (Figure 1c) when the melt retreated to the percolation facies and the extent decreased to $44.9 \%$ of the ice sheet surface. However, the melt became extensive again on 29 July (Figure 1d) when the melt extent increased to $79.2 \%$ of the ice sheet surface. This melt covered a significant part of the dry snow facies including the area around Summit Station where melt was barely detectable by OS2 and SSMIS data, thus indicating a brief weak melt at that location. This melt, while notable, was not as extensive as the earlier event on 12 July. The 29 July melt event shows the satellite capability to observe the spatial heterogeneity of melt processes, indicating that a melt event occurring at Summit does not 

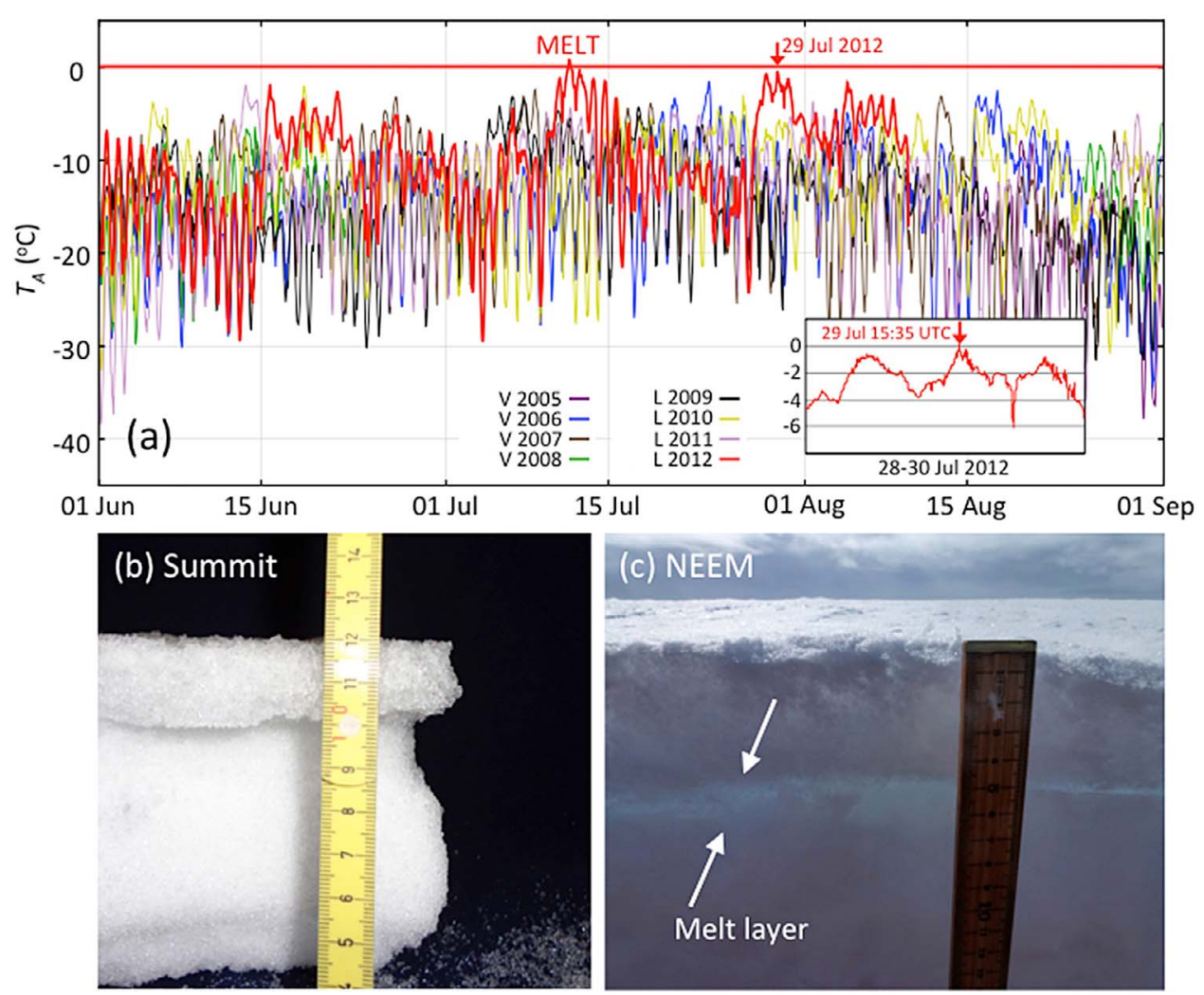

Figure 2. In-situ temperature and field observations. (a) Air temperature, $T_{A}$, measured at the NOAA Summit Station in June-September of 2005-2012 from hourly-averaged data. The inset shows the plot of temperature at every minute for 28-30 July 2012. The red arrows mark the peak temperature time on 29 July 2012. Evidence of melt from field observations: (b) sample of the ice crust and underlying snow from Summit Station, and (c) image of the near-surface melt layer in a snow pit at NEEM site. Photo credits: Figure 2b, Mary Albert; Figure 2c, Kaitlin Keegan.

necessarily indicate that melt occurs everywhere else on the ice sheet.

\section{Field Verification}

[21] To verify the extreme melt events observed by the satellites, we have compiled temperature measurements from a number of weather stations as well as field observations of snow and ice conditions. Temperature data, available from many operational automatic weather stations (AWS) in the Greenland Climate Network (GC-Net) [Steffen and Box, 2001] at key locations across the ice sheet (http://cires.colorado.edu/ science/groups/steffen/gcnet/), show values hovering above the melting point during the time of the extreme melt event.

[22] At Summit where melt may be the least likely to occur, a good set of nominal 2-m air temperature data are available from a National Oceanic and Atmospheric Administration (NOAA) climate observatory, where the temperature sensors are serviced daily, are actively (fan) ventilated, and the resulting data are quality controlled. This NOAA Baseline Observatory $\left(72.58^{\circ} \mathrm{N}\right.$ and $38.48^{\circ} \mathrm{W}$ at 3216 masl) is maintained in cooperation with the National Science Foundation (http://www.esrl. noaa.gov/gmd/obop/sum/index.html). Figure 2a presents a plot of temperature data from the NOAA Summit Station for June-September in each year since 2005 when the station began operations. Hourly-averaged temperature values hovering about or above melting are clearly seen around the time of the extreme melt event observed by the satellite sensors. Some peaks of hourly-averaged temperature data were slightly below the melting point as seen on the plot around 29 July 2012. On a close examination of the data at a higher temporal resolution, one of these peaks actually contained a single minute average value above $0^{\circ} \mathrm{C}$ (inset in Figure 2a). This is consistent with the weak melt detected by OS2 on 29 July 2012 at Summit.

[23] Actual field observations of snowmelt and meltwater provide the best direct evidence of the melt event. At Summit on 12 July 2012, the surface of the snow became slushy. The melt was spatially continuous, evident in all directions outward from the Summit camp. Cooling conditions after that caused re-freezing, and by the time a group of the Dartmouth Integrative Graduate Education and Research Traineeship (http://www.igert.org/) arrived at Summit on 20 July, the surface melt had completely refrozen into an ice crust almost 2 -cm thick, and a fresh snow layer approximately $0.5 \mathrm{~cm}$ thick had fallen on top. These field observations confirm both the melt event on 12 July and the refreezing process afterward.

[24] After a significant melt like this occurs, an ice layer is formed by meltwater that is refrozen in the firn layer of the ice sheet, providing a record of the melt event. From observations in a snow pit, the ice layer was clearly identified from the underlying layers and from the fresh snow on top by both its appearance and cohesiveness. This layer was sufficiently strong such that large segments of the layer could be cut and removed for inspection. Figure $2 b$ is a photo of a sample of the ice layer from the extreme melt event at Summit and the adjacent underlying snow layer; the loose surface snow had been brushed off, and the underlying snow beneath the right 
side of the sample has been brushed away. The sample was retrieved from the snow on 22 July 2012. The ice grains within the refrozen melt layer are larger, more rounded, and more strongly sintered together than the grains in adjacent layers.

[25] At the North Greenland Eemian Ice Drilling site (NEEM at $77.45^{\circ} \mathrm{N}$ and $51.06^{\circ} \mathrm{W}$ ), which is at a lower elevation in an area northwest of Summit (see Figure 1 for the location), the field team observed that the surface crust was approximately $1-\mathrm{cm}$ thick, and also was spatially continuous in all directions. NEEM experienced above-freezing temperatures for six consecutive days from 10 to 15 July 2012 , with two rain events on 11 and 13 July. These produced multiple ice layers in the firn as the water drained through the firn; the most notable ice layers occurred at depths of $\sim 5 \mathrm{~cm}, 20 \mathrm{~cm}$, and $\sim 69 \mathrm{~cm}$. Figure $2 \mathrm{c}$ shows the surface melt layer at a depth of $\sim 5 \mathrm{~cm}$, which had been buried by $\sim 4 \mathrm{~cm}$ of snow following the melt event. The surface melt layers, as well as the layers at $20 \mathrm{~cm}$ and $\sim 69 \mathrm{~cm}$ depths, are spatially continuous at NEEM. The greater number of days above freezing and the rains around NEEM caused more extensive melt layering than occurred at Summit.

\section{Discussions and Conclusion}

[26] A likely cause of this extreme melt event was an anomalous ridge of warm air, acting as a strong heat dome that became stagnant over Greenland. The heat dome is identifiable in the 500-hPa height anomaly from the National Center for Environments Prediction (NCEP) Climate Data Assimilation System (CDAS, http://www.cpc.ncep.noaa.gov/products/ intraseasonal/). Note that the $500-\mathrm{hPa}$ geopotential height anomaly over Greenland, defined as the Greenland Blocking Index [Hanna et al., 2012], was the strongest for June 2012 in the 1948-2012 NCEP Reanalysis record for June [Overland et al., 2012]. The ridge was one of a series that has dominated the weather across Greenland since the end of May, with each successive ridge being stronger than the previous one. The heat dome began to dissipate by 16 July 2012. Then, another ridge that was not as strong as the earlier one came in and dominated mainly in southern Greenland. This later dome coincided with the melt on 29 July, which was not as extensive as the earlier extreme melt event.

[27] Historically, melt is rare in cold polar areas at high altitudes like Summit on the Greenland ice sheet. A pronounced ice layer from a significant melt event, which is clearly evident in documented firn cores at many sites in Greenland, is the 1889 ice layer [Clausen et al., 1988]. Records from the GISP2 deep ice core, which was retrieved at Summit, show that "thin ice layers which reflect melt from a single summer" occurred in the ice core only eight times between 500 and 1994 [Meese et al., 1994].

[28] From the same core, Alley and Anandakrishnan [1995] studied melt layers from the upper $1565 \mathrm{~m}$ of the GISP2 core over a time period of 10,000 years. However, the frequency of melt occurrence varies widely in time as identified by ice layers in ice cores. Prior to the 19th-century event, another significant melt event occurred about 680 years earlier [Meese et al., 1994] preceded by several events in the Medieval Warm Period (a.k.a. the Medieval Climatic Anomaly). Melt occurred once in about 250 years from 1000 to $4000 \mathrm{BP}$ (referenced to 1950) and once in about 82 years from $5000 \mathrm{BP}$ to $8500 \mathrm{BP}$ according to Alley and
Anandakrishnan [1995]. These significant melt events are widely sporadic in different periods of the Holocene, clearly exhibiting their non-stationary behavior. Thus, a single average value of melt frequency is not necessarily applicable to represent climate change at a given time period in the past, the present, or the future.

[29] In summary, this paper highlights the satellite capability for melt detection, combining data from multiple satellites to provide full coverage without gaps across the entire ice sheet. The satellite observations captured the GIS extreme melt event in its entirety within a short latency, allowing scientists to plan for timely science investigations given the rarity of the event. Given the vast GIS extent of 1.71 million $\mathrm{km}^{2}$, impacts of this extreme melt event remain to be investigated; for example, the mass balance of the ice sheet, surface heat exchange in the boundary layer across GIS, or atmospheric chemical processes involving different states of the snow cover on GIS. Thus, the 2012 melt event is a historic record that may excite many new scientific research studies.

[30] Acknowledgments. The research carried out at the Jet Propulsion Laboratory, California Institute of Technology, and at NASA Goddard Space Flight Center (GSFC) was supported by the National Aeronautics and Space Administration (NASA) Cryospheric Sciences Program. We would like to acknowledge the support of the NASA Headquaters Science Innovation Fund (SIF), which helped to fund ongoing work at GSFC to blend the melt maps from the three different instruments. The work at the City College of New York was supported by the NASA Cryospheric Program and the National Science Foundation grant ARC 0909388. Field observations of the melt at Summit and NEEM were carried out under support from the National Science Foundation grant IGERT-0801490 to Dartmouth College. Near-surface air temperature data in July 2012 are courtesy of Thomas Mefford (NOAA Earth System Research Laboratory Boulder, Colorado and Cooperative Institute for Research in Environmental Sciences, University of Colorado at Boulder) with additional processing by Michael J. Schnaubelt (University of Maryland, Baltimore County, Joint Center for Earth Systems Technology and Department of Physics, Baltimore, Maryland).

[31] The Editor thanks Edward Hanna for his assistance in evaluating this paper.

\section{References}

Abdalati, W., and K. Steffen (1997), Snowmelt on the Greenland ice sheet as derived from passive microwave satellite data, J. Clim., 10(2), 165-175, doi:10.1175/1520-0442(1997)010<0165:SOTGIS >2.0.CO;2.

Ackerman, S. A., K. I. Strabala, P. W. P. Menzel, R. A. Frey, C. C. Moeller, and L. E. Gumley (1998), Discriminating clear sky from clouds with MODIS, J. Geophys. Res., 103(D24), 32,141-32,157, doi:10.1029/ 1998JD200032.

Ackerman, S. A., R. E. Holz, R. Frey, E. W. Eloranta, B. Maddux, and M. McGill (2008), Cloud detection with MODIS. Part II: Validation, J. Atmos. Oceanic Technol., 25, 1073-1086, doi:10.1175/2007JTECHA1053.1.

Alley, R., and S. Anandakrishnan (1995), Variations in melt-layer frequency in the GISP2 ice core: implications for Holocene summer temperatures in Greenland, Ann. Glaciol., 21, 64-70.

Allison, I. N. L., et al. (2009), The Copenhagen Diagnosis, 2009: Updating the World on the Latest Climate Science, 60 pp., CCRC, Univ. of New South Wales, Sydney, N. S. W., Australia.

Benson, C. S. (1962), Stratigraphic studies in the snow and firn of the Greenland ice sheet, SIPRE Res. Rep. 70, U.S. Army Snow and Ice Permafrost Res. Establ., Wilmette, Ill.

Clausen, H. B., N. S. Gundestrup, S. J. Johnsen, R. Bindschadler, and J. Zwally (1988), Glaciological investigations in the Crete area, central Greenland: A search for a new deep-drilling site, Ann. Glaciol., 10, $10-15$.

Cuffey, M. C., and S. J. Marshall (2000), Substantial contribution to sealevel rise during the last interglacial from the Greenland ice sheet, Nature, 404(6778), 591-594, doi:10.1038/35007053.

Hall, D. K., J. Key, K. A. Casey, G. A. Riggs, and D. J. Cavalieri (2004), Sea ice surface temperature product from MODIS, IEEE Trans. Geosci. Remote Sens., 42, 1076-1087, doi:10.1109/TGRS.2004.825587.

Hall, D. K., J. E. Box, K. A. Casey, S. J. Hook, C. A. Shuman, and K. Steffen (2008), Comparison of satellite-derived ice and snow surface temperatures over Greenland from MODIS, ASTER, ETM+ and in-situ 
observations, Remote Sens. Environ., 112(10), 3739-3749, doi:10.1016/j. rse.2008.05.007.

Hall, D. K., S. V. Nghiem, C. B. Schaaf, N. E. DiGirolamo, and G. Neumann (2009), Evaluation of surface and near-surface melt characteristics on the Greenland ice sheet using MODIS and QuikSCAT data, J. Geophys. Res., 114, F04006, doi:10.1029/2009JF001287.

Hall, D. K., J. C. Comiso, N. E. DiGirolamo, C. A. Shuman, J. R. Key, and L. S. Koenig (2012), A satellite-derived climate-quality data record of the clear-sky surface temperature of the Greenland ice sheet, J. Clim., 25(14), 4785-4798, doi:10.1175/JCLI-D-11-00365.1.

Hanna, E., et al. (2008), Increased runoff from melt from the Greenland ice sheet: A response to global warming, J. Clim., 21, 331-341, doi:10.1175/ 2007JCLI1964.1.

Hanna, E., J. M. Jones, J. Cappelen, S. H. Mernild, L. Wood, K. Steffen, and P. Huybrechts (2012), The influence of North Atlantic atmospheric and oceanic forcing effects on 1900-2010 Greenland summer climate and ice melt/runoff, Int. J. Climatol., doi:10.1002/joc.3475, in press.

Hollinger, J., R. Lo, G. Poe, R. Savage, and J. Pierce (1987), Special Sensor Microwave/Imager User's Guide, Nav. Res. Lab., Washington, D. C.

Key, J., and M. Haefliger (1992), Arctic ice surface temperature retrieval from AVHRR thermal channels, J. Geophys. Res., 97, 5885-5893, doi:10.1029/92JD00348.

Klein, L. A., and C. Swift (1977), An improved model for the dielectric constant of sea water at microwave frequencies, IEEE Trans. Antennas Propag., 25(1), 104-111, doi:10.1109/TAP.1977.1141539.

Meese, D., A. J. Gow, P. Grootes, P. A. Mayewski, M. Ram, M. Stuiver, K. C. Taylor, E. D. Waddington, and G. A. Zielinski (1994), The accumulation record from the GISP2 core as an indicator of climate change throughout the Holocene, Science, 266, 1680-1682, doi:10.1126/ science.266.5191.1680.

Mote, T. (2007), Greenland surface melt trends 1973-2007: evidence of a large increase in 2007, Geophys. Res. Lett., 34, L22507, doi:10.1029/ 2007GL031976.

Mote, T. L., and M. R. Anderson (1995), Variations in melt on the Greenland ice sheet based on passive microwave measurements, J. Glaciol., 41, 51-60.
Nghiem, S. V., K. Steffen, R. Kwok, and W.-Y. Tsai (2001), Detection of snow melt regions on the Greenland ice sheet using diurnal backscatter change, J. Glaciol., 47(159), 539-547, doi:10.3189/172756501781831738.

Nghiem, S. V., K. Steffen, G. Neumann, and R. Huff (2005), Mapping of ice layer extent and snow accumulation in the percolation zone of the Greenland ice sheet, J. Geophys. Res., 110, F02017, doi:10.1029/ 2004JF000234.

Overland, J. E. E., J. Francis, E. Hanna, and M. Wang (2012), The recent shift in early summer arctic atmospheric circulation, Geophys. Res. Lett., doi:10.1029/2012GL053268, in press.

Scambos, T. A., T. M. Haran, and R. Massom (2006), Validation of AVHRR and MODIS ice surface temperature products using in situ radiometers, Ann. Glaciol., 44(1), 345-351, doi:10.3189/172756406781811457.

SCAT-DP Team (2010), Oceansat-2 Scatterometer algorithms for sigma-0, processing and products format, version 1.1, report, 32 pp., Space Appl. Cent., Ahmedabad, India.

Steffen, K., and J. Box (2001), Surface climatology of the Greenland ice sheet: Greenland climate network 1995-1999, J. Geophys. Res., 106(D24), 33,951-33,964, doi:10.1029/2001JD900161.

Steffen, K., S. V. Nghiem, R. Huff, and G. Neumann (2004), The melt anomaly of 2002 on the Greenland ice sheet from active and passive microwave satellite observations, Geophys. Res. Lett., 31, L20402, doi:10.1029/2004GL020444.

Tedesco, M. (2007), Snowmelt detection over the Greenland ice sheet from SSM/I brightness temperature daily variations, Geophys. Res. Lett., 34, L02504, doi:10.1029/2006GL028466.

Tedesco, M., M. Serreze, and X. Fettweis (2008), Diagnosing the extreme surface melt event over southwestern Greenland in 2007, Cryosphere, 2, 159-166, doi:10.5194/tc-2-159-2008.

Tiuri, M. E., A. H. Sihvola, E. G. Nyfors, and M. T. Hallikainen (1984), The complex dielectric constant of snow at microwave frequencies, IEEE J. Oceanic Eng., 9(5), 377-382, doi:10.1109/JOE.1984.1145645.

Tsang, L., J. A. Kong, and R. T. Shin (1985), Theory of Microwave Remote Sensing, John Wiley, New York. 